\title{
Atividade antifúngica do extrato de jambu (Acmella oleracea) sobre o crescimento de micelial Rhizoctonia solani
}

R. solani é um parasita necrotrófico, habitante natural do solo. É um fungo polífago, pois ataca diversas espécies vegetais. R. solani pode ser transmitido pelas sementes, porém, raramente isto ocorre, motivo pelo qual a semente não é considerada a principal fonte de inóculo desse patógeno. Esse fungo, estando presente no solo e/ou nas sementes, além de ocasionar perdas significativas na fase de plântulas (falha no estande), pode servir ainda como inóculo para culturas subsequentes. Diante do prejuízo causado por essa doença se fez estudo fúngico da avaliação a atividade do extrato de Jambu em diferentes concentrações sobre o sobre o crescimento micelial do fungo Rhizoctonia solani. Foram coletadas $100 \mathrm{~g}$ das folhas de Jambu, estas foram trituradas no liquidificador até chegar no estado líquido. O Fungo fitopatogênico Rhizoctonia solani foi cedido pelo laboratório de Fitopatologia da Universidade Federal Rural da foram trituradas no liquidificador até chegar no estado líquido. O Fungo fitopatogênico Rhizoctonia solani foi cedido pelo laboratório de Fitopatologia da Universidade Federal Rural da no centro da placa de Petri contendo os tratamentos citados. Delineamento experimental do trabalho, foi inteiramente casualizado (DIC) realizado no laboratório de Fitopatologia da própria universidade (UFRA), executado com 5 tratamentos e 5 repetições, denominado de T1, T2, T3, T4 e T5, o T1 foi selecionado para ser o tratamento testemunha. Alíquotas do extrato foram condicionadas ao meio de cultura BDA, nas seguintes concentrações: $0 \mathrm{ml}, 2 \mathrm{ml}, 4 \mathrm{ml}, 6 \mathrm{ml}$ e $8 \mathrm{ml}$. Os dados foram submetidos à análise de variância, e as médias, comparadas pelo teste de Tukey, a 5\% de probabilidade, utilizando o programa estatístico SISVAR 7.6. interação do extrato vegetal de Jambu sobre a inibição do crescimento micelial de Rhizoctonia solani foi significativo, sendo a maior porcentagem de inibição proporcional ao aumento das concentrações.

Palavras-chave: Controle alternativo; Inibição; Fitopatologia.

\section{Antifungal activity of jambu (Acmella oleracea) extract on the growth of mycelial Rhizoctonia solani}

\begin{abstract}
R. solani is a necrotrophic parasite, a natural inhabitant of the soil. It is a polyphagous fungus, as it attacks several plant species. R. solani can be transmitted by the seeds, however, this rarely occurs, reason why the seed is not considered the main source of inoculum of this pathogen. This fungus, being present in the soil and/or in the seeds, in addition to causing significant losses in the seedling phase (failure in the stand), can also serve as an inoculum for subsequent cultures. In view of the damage caused by this disease, a fungal study was carried out to evaluate the activity of Jambu extract in different concentrations on the mycelial growth of the fungus Rhizoctonia solani. 100g of the Jambu leaves were collected, these were crushed in a blender until they reached the liquid state. The phytopathogenic fungus Rhizoctonia solani was provided by the Phytopathology laboratory of the Federal Rural University of the Amazon (UFRA). The until they reached the liquid state. The phytopathogenic fungus Rhizoctonia solani was provided by the Phytopathology laboratory of the Federal Rural University of the Amazon (UFRA). The
plant extract antifungal test used Jambu extract added in Agar-Potato-Dextrose (BDA). The mycelium discs of the pathogen were deposited in the center of the Petri dish containing the treatments mentioned. experimental design of the work, was completely randomized (DIC) performed in the phytopathology laboratory of the university itself (UFRA), performed with 5 treatments and 5 repetitions, called T1, T2, T3, T4 and T5, T1 was selected to be the witness treatment. aliquots of the extract were conditioned to the BDA culture medium, in the following concentrations: $0 \mathrm{ml}, 2 \mathrm{ml}, 4 \mathrm{ml}, 6 \mathrm{ml}$ and $8 \mathrm{ml}$. The data were submitted to analysis of variance, and the means, compared by the Tukey test, at $5 \%$ probability, using the statistical program SISVAR 7.6. interaction of the Jambu plant extract on the inhibition of mycelial growth of Rhizoctonia solani was significant, with the highest percentage of inhibition proportional to the increase in concentrations.
\end{abstract}

Keywords: Alternative control; Inhibition; Phytopathology.

Topic: Proteção de Plantas e Fitotecnia

Reviewed anonymously in the process of blind peer.
Received: 10/11/2020

Approved: $15 / 02 / 2021$
Sayure Mariana Raad (iD)

Universidade Federal Rural da Amazônia, Brasil

http://lattes.cnpq.br/8281827404307486

http://orcid.org/0000-0002-4127-7351

raadsayure@gmail.com

Erick dos Santos Ribeiro

Universidade Federal Rural da Amazônia, Brasil

http://lattes.cnpq.br/9915795223042598

ericksantos39@hotmail.com

Rayanne de Jesus Castro (D)

Universidade Federal Rural da Amazônia, Brasil

http://lattes.cnpq.br/9088824012673103

http://orcid.org/0000-0001-7460-4390

castrorayanne60@gmail.com

\author{
Francimary da Silva Carneiro \\ Universidade Federal Rural da Amazônia, Brasil \\ http://lattes.cnpq.br/8657235544233319 \\ http://orcid.org/0000-0002-1693-8779 \\ francimarycarneiro@gmail.com \\ Mayra Piloni Maestri (iD \\ Universidade Federal Rural da Amazônia, Brasil \\ http://lattes.cnpq.br/2687102042811310 \\ http://orcid.org/0000-0002-8936-952X \\ mayrapmaestri@hotmail.com
}




\section{INTRODUÇÃO}

O jambu (Spilanthes oleracea L.) é uma Asteraceae nativa da região amazônica, hortaliça herbácea perene, semiereta e de ramos decumbentes (MARTINS et al., 2012). Conhecido, no Pará, por vários nomes populares como: agrião do Pará, agrião do Brasil, agrião do Norte, jabuaçú, erva maluca, jaburama, botão de ouro, etc. (COUTINHO et al., 2006).

As flores e as folhas têm uso medicinal na elaboração de infusões no tratamento de anemia, dispepsia, malária, afeç̧ões da boca (dor de dente) e da garganta e também como antibiótico e anestésico, sendo assim de fundamental importância sua caracterização fitoquímica (BORGES et al., 2010).

Crescente resistência dos microrganismos patogênicos, frente aos produtos sintéticos. Faz necessário os controles alternativos desenvolvidos com extratos brutos ou óleos essenciais, obtidos a partir de plantas medicinais têm indicado o potencial dos mesmos no controle de fitopatógenos (CUNICO et al., 2003) uma planta medicinal pode ser definida como qualquer vegetal que produza, em quantidade considerável substâncias biologicamente ativas utilizadas direta ou indiretamente como medicamento (CASTRO et al., 2004).

Essas plantas possuem compostos secundários, compostos não vitais às plantas, mas com função de proteção contra pragas e doenças e atração de polinizadores, que tanto podem ter ação fungitóxica (ação antimicrobiana direta) como eliciadora, ativando mecanismos de defesa nas plantas (ação antimicrobiana indireta) (STANGARLIN et al., 1999).

Compostos secundários presentes em plantas medicinais podem desempenhar funções importantes em interações planta-patógeno, através de ação antimicrobiana direta ou ativando mecanismos de defesa de outras plantas que venham a ser tratadas com esses compostos (SCHWAN-ESTRADA, 2003).

O fungo Rhizoctonia solani pertencente ao grupo de anastomose 1 IA (AG-1 IA) é um dos patógenos mais importantes afetando a cultura da soja no Brasil (BASSETO et al., 2007). Rhizoctonia solani, geralmente, é encontrado na forma micelial, pois não produz esporos e utilizam como forma de sobrevivência no solo a formação de estruturas globulosas denominadas escleródios ou esclerócios (9) que podem sobreviver no solo por, no mínimo, um ano (DIAS et al., 2013).

Desse modo o presente consistirá na avaliação a atividade antifúngica do extrato de Jambu em diferentes concentrações sobre o sobre o crescimento micelial do fungo Rhizoctonia solani.

\section{METODOLOGIA}

As folhas de jambu (Acmella oleracea) para a produção do extrato vegetal foram coletadas em áreas de pequenos agricultores de Santa Barbará-PA. Para o preparo do extrato foram coletadas $100 \mathrm{~g}$ das folhas de Jambu, estas foram trituradas no liquidificador até chegar no estado líquido. O Fungo fitopatogênico Rhizoctonia solani foi cedido pelo laboratório de Fitopatologia da Universidade Federal Rural da Amazônia (UFRA).

Para a avaliação da atividade antifúngica do extrato vegetal utilizou-se o extrato de Jambu 
acrescentados em Ágar-Batata-Dextrose (BDA). Os discos de micélio do patógeno foram depositados no centro da placa de Petri contendo os tratamentos citados. Estas foram vedadas com filme plástico e incubadas á $28^{\circ} \mathrm{C}$ em luz contínua.

O delineamento experimental do trabalho, foi inteiramente casualizado (DIC) realizado no laboratório de Fitopatologia da própria universidade (UFRA), executado com 5 tratamentos e 5 repetições, denominado de $\mathrm{T} 1, \mathrm{~T} 2, \mathrm{~T} 3, \mathrm{~T} 4$ e T5, o T1 foi selecionado para ser o tratamento testemunha (sem a presença do extrato no meio de cultura).

As alíquotas do extrato foram condicionadas ao meio de cultura BDA, nas seguintes concentrações: $0 \mathrm{ml}, 2 \mathrm{ml}, 4 \mathrm{ml}, 6 \mathrm{ml} \mathrm{e} 8 \mathrm{ml}$. A avalição dos discos de micélio nas placas foi realizada através de medições diárias do diâmetro das colônias em sentidos opostos. A partir dos resultados obtidos, determinou-se a porcentagem de inibição do crescimento micelial (PIC), utilizando-se a fórmula universal:

PIC: (Diâmetro da testemunha- Diâmetro do tratamento/Diâmetro da testemunha)x100

Os dados foram submetidos à análise de variância, e as médias, comparadas pelo teste de Tukey, a 5\% de probabilidade, utilizando o programa estatístico SISVAR 7.6.

\section{RESULTADOS E DISCUSSÃO}

O efeito da interação do extrato vegetal de Jambu sobre a inibição do crescimento micelial de Rhizoctonia solani foi significativo, sendo a maior porcentagem de inibição proporcional ao aumento das concentrações (Figura 1).

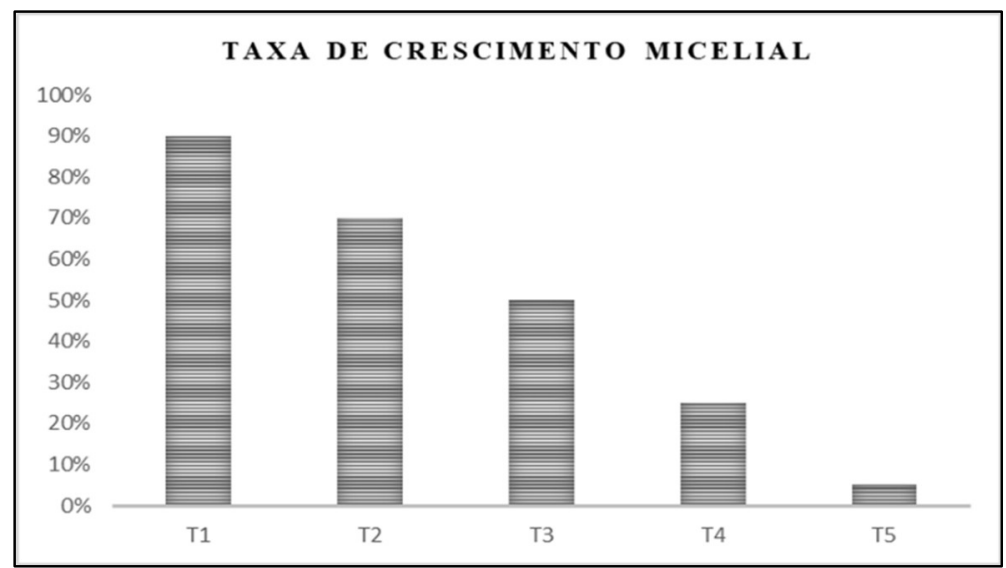

Figura 1: Atividade antifúngica do extrato vegetal de Jambu em diferentes concentrações sobre Rhizoctonia solani.

Analisando a figura 1 é possível observar que o tratamento T5, correspondente a concentração de 8 $\mathrm{ml}$, obteve o melhor resultado com um crescimento analisado pelo diâmetro do micélio o qual obteve um crescimento de $5 \%$ comparada a testemunha, logo, a sua taxa de inibição foi de $95 \%$.

Os resultados obtidos com quitosana como fungistático no crescimento micelial demonstraram que quitosana a $0,25,0,5,1$ e $2 \%$ de concentração reduziram o crescimento micelial de $R$. solani. Outros resultados obtidos como controle alternativo como no experimento montado com controle alternativo "in vitro" de $R$. solani, verificou-se inibição total do crescimento pelo extrato pirolenhoso na dose de $1 \mathrm{~mL}$ e a manipueira teve melhores resultados com a dose de $0,25 \mathrm{~mL}$ (DAVID et al., 2018). 
É um bioensaio conduzido com extrato de cravo-da-índia revelou maior eficácia no controle dos fitopatógenos de R. solani concentrações de 7,4\%, 7,5\%, 8,9\% e 7,0\% (VENTUROSO et al., 2011). O açafrão aplicado em uma ação antifúngica levou a uma inibição superior a 50\% no crescimento R. solani $61,1 \%$ (AMARAL et al., 2015). O extrato vegetal de Jambu ao longo do experimento demostrou grande eficiência com elevadas concentrações, representado grande potencial para controle fitossanitário de R. solani.

\section{CONCLUSÕES}

Diante das análises dos resultados apresentados neste trabalho, pode-se dizer que maior porcentagem concentrações extrato vegetal de Jambu sobre a inibição do crescimento micelial de Rhizoctonia solani foi significativo apresentado grau satisfatório. Destacando o tratamento T5, que teve o maior poder inibitório quando comparado à testemunha.

\section{REFERÊNCIAS}

AMARAL, M. F. Z. J.; BARA, M. T. F.. Avaliação da atividade antifúngica de extratos de plantas sobre o crescimento de fitopatógenos. Revista Eletrônica de Farmácia Suplemento, v.2, n.2, p.5-8, 2005

BORGES, L. S.; MARQUES, M. O. M.; LIMA, G. P. P.. Composição do óleo essencial de jambu cultivado sob adubação orgânica. Hortic. Bras., v.28, n.2, 2010.

BASSETO, M. A.; CERESINI, P. C.; FILHO, W. V. V.. Severidade da mela da soja causada por Rhizoctonia solani AG-1 IA em função de doses de potássio. Summa Phytopathol. Botucatu, v.33, n.1, p.56-62, 2007.

COUTINHO, L. N.; APARECIDO, C. C.; FIGUEIREDO, M. B.. Galhas e deformações em Jambu (Spilanthes oleraceae) causadas por Tecaphora spilanthes (Ustilaginales). Summa Phytopathol., Botucatu, v.32, n.3, p.283-285, 2006.

CUNICO, M. M.; MIGUEL, O. G.; MIGUEL, M. D.; CARVALHO, J. L. S.; LIMA, C. P.; AUER, C. G.; GRIGOLETTI JÚNIOR, A.. Estudo da atividade antifúngica de Ottonia martiana Miq., Piperaceae: um teste in vivo. Visão Acadêmica, Curitiba, v.4, n.2, p.77-82, 2003. DOI: http://doi.org/10.5380/acd.v4i2.526

CASTRO, H. G.; FERREIRA, F. A.. Contribuição ao estudo das plantas medicinais metabólitos secundários. 2 ed. Visconde do Rio Branco: Suprema, 2004.
DAVID, G.; PAULO, C.; PERES, W.. Controle alternativo 'in vitro' de Rhizoctonia solani com extratos vegetais em Alta Floresta - MT. In: CADERNOS DE AGROECOLOGIA, 10. Anais. 2018.

DIAS, P. P.; BERBARA, R. L. L.; FERNANDES, M. C. A.. Controle de Rhizoctonia solani e Fusarium oxysporum f.sp. phaseoli por biopreparados de isolados de Trichoderma spp. Summa Phytopathol., Botucatu, v.39, n.4, p.258-262, 2013

MARTINS, C. P. S.; MELO, M. T. P.; HONÓRIO, I. C. G.; D'ÁVILA, V. A.; CARVALHO JÚNIOR, W. G. O.. Caracterização morfológica e agronômica de acessos de jambu (Spilanthes oleracea L.) nas condições do Norte de Minas Gerais. Rev. Bras. PI. Med., Botucatu, v.14, n.2, p.410-413, 2012.

STANGARLIN, J. R.; SCHWAN-ESTRADA, K. R. F.; CRUZ, M. R. S.; NOZAKI, M. H.. Plantas medicinais e o controle alternativo de fitopatógenos. Biotecnologia, Ciência e Desenvolvimento, Brasília, v.11, v.3, p.16-21, 1999.

VENTUROSO, L. R.; BACCHI, L. M. A.; GAVASSONI, W. L.; CONUS, L. A.; PONTIM, B. C. A.; SOUZA, F. R.. Inibição do crescimento in vitro de fitopatógenos sob diferentes concentrações de extratos de plantas medicinais. Arq. Inst. Biol., São Paulo, v.78, n.1, p.89-95, 2011.

A CBPC - Companhia Brasileira de Produção Científica (CNPJ: 11.221.422/0001-03) detém os direitos materiais desta publicação. Os direitos referem-se à publicação do trabalho em qualquer parte do mundo, incluindo os direitos às renovações, expansões e disseminações da contribuição, bem como outros direitos subsidiários. Todos os trabalhos publicados eletronicamente poderão posteriormente ser publicados em coletâneas impressas sob coordenação da Sustenere Publishing, da Companhia Brasileira de Produção Científica e seus parceiros autorizados. Os (as) autores (as) preservam os direitos autorais, mas não têm permissão para a publicação da contribuição em outro meio, impresso ou digital, em português ou em tradução. 